\title{
ALGUNAS REFLEXIONES SOBRE LA SÁTIRA EN CERVANTES
}

"The subject has not yet received the study it deserves". Estejuicio de Riley, formulado en 1976, sigue siendo válido hasta la fecha ${ }^{1}$. Claro está, no es un tema que pueda ser agotado en un artículo, ni siquiera, quizás, en un estudio de dimensiones más amplias. La sátira es una corriente que fluye difusa en la mayoría de las obras de Cervantes, asomándose en algunas como aspecto dominante, pero nunca fácil de separar de otros aspectos afines, como son la agudeza apotegmática, el didactismo moral, etc. Por ello, me limitaré a examinar una ambigüedad central en Cervantes y a esbozar algunas de sus repercusiones prácticas. Si bien ni aquélla ni éstas han pasaso inadvertidas para los críticos, siguen siendo objeto de interpretaciones parciales y desequilibradas.

El punto de arranque obligatorio es la afirmación hecha por Cervantes en el capítulo cuatro del Viaje del Parnaso:

\section{Nunca voló la humilde pluma mía}

1 El estudio más amplio es el de Alban Forcione, Cervantes and the humanist vision, Princeton University Press, Princeton, NJ, 1982, pp. 281-296, cuyo argumento se prolonga en Cervantes and the mystery of lawlessness, Princeton University Press, Princeton, 1984. La tesis de Forcione, a pesar de su erudición y frecuente perspicacia, me parece falseada por su empeño en convertir a Cervantes en un erasmista tardío, que contempla con profunda desazón la cultura y sociedad en torno suyo. Esta óptica le lleva a exagerar de modo exorbitante la mordacidad y el pesimismo de las dos novelas satíricas que estudia: El licenciado Vidriera y El coloquio de los perros. Otros estudios que versan sobre el tema son el artículo de E. C. RiLeY, mencionado en el texto, "Cervantes and the cynics (El licenciado Vidriera and El coloquio de los perros)", BHS, 53 (1976), 189-199, y, en general, la mayor parte de los libros o artículos que tratan de estas dos novelas de Cervantes. Para ahorrar espacio, remito a la bibliografía de Riley y los índices de Forcione. 
por la región satírica, bajeza

que a infames premios y desgracias guía ${ }^{2}$.

Dado que la declaración aparece en una obra satírica, parece plantear una paradoja absurda. Desde luego, la dificultad es muy fácil de resolver si nos atenemos a la distinción que hace Don Quijote entre la sátira ilegítima y la legítima: "Riña vuesa merced a su hijo si hiciere sátiras que perjudiquen las honras ajenas [...] pero si hiciere sermones al modo de Horacio, donde reprehenda los vicios en general, como tan elegantemente él lo hizo, alábele"'3. Esto cuadra con la licencia otorgada por el perro Cipión a su compañero Berganza para que "murmures un poco de luz, y no de sangre: quiero decir que señales, y no hieras ni des mate a ninguno en cosa señalada; que no es buena la murmuración, aunque haga reír a muchos, si mata a uno"4. Este tipo de prevención es lugar común; lo encontramos en Carballo, Cascales, El Pinciano y otros preceptistas ${ }^{5}$. Carballo dice: "Satyra se llama la compostura, en que se reprehende o vitupera algun vicioso o algun vicio. Pero ya esta recibida por murmuración, apodo, o matraca, y por fisgar, por la malicia de los que en nuestros tiempos usan mal dellas"'. Tanto los escritores cultos (Quevedo, Lope, Góngora) como los poetas plebeyos daban motivos sobrados para esta observación. Como se sabe, la aversión de Cervantes por la sátira difamatoria fue en parte el envés de su concepción idealizada de la buena poesía ${ }^{6}$. Sin embargo, el problema de la

${ }^{2}$ Cito por la edición de F. RodríGuez Marín, C. Bermejo, Madrid, 1935 , p. 52.

${ }^{3}$ Don Quijote II, 17, ed. Luis Murillo, 3 ts., Castalia, Madrid, 1978, t. 2, pp. 156-157.

${ }^{4}$ Cito El coloquio de los perros por la edición de F. Rodríguez Marín en Cervantes: Novelas ejemplares, 2 ts., Espasa-Calpe, Madrid, 1935, t. 2, p. 224. Cito El licenciado Vidriera por la misma edición.

${ }^{5}$ Véanse Luis Alonso de Carballo, Cisne de Apolo (1602), ed. A. Porqueras Mayo, 2 ts., CSIC, Madrid, 1958, t. 2, p. 62; Francisco de CascaLES, Tablas poéticas (1617), ed. Benito Brancaforte, Espasa-Calpe, Madrid, 1975, pp. 180-184; Alonso López Pinciano, Philosophia antigua poetica (1596), ed. A. Carballo Picazo, 3 ts., CSIC, Madrid, 1953, t. 1, pp. 284-285, t. 2, pp. 233 ss., 289-290.

${ }^{6}$ Véase Riley, art. cit. pp. 197-198. Entre la tradición de poemas mitológico-burlescos de que ha brotado el Viaje del Parnaso se encuentran la "Sátira apologética en defensa del divino Dueñas" (1569), del canónigo sevillano Francisco de Pachecho, y el romance del sevillano Juan de la Cueva, titulado "Cómo los poetas conquistaron el Parnaso y lo ganaron, y Apolo y las Musas huyeron dél” (1588). El primer poema fue publicado por F. RodríGuez MA- 
legitimidad de la maledicencia "artística" no fue planteado solamente por la poesía satírica, ni siquiera por la sátira en conjunto; como lo demuestra la tesis de Monique Joly, tiene una trascendencia cultural mucho más amplia ${ }^{7}$.

Pero si bien esta solución de la paradoja es convincente, no toma en cuenta el tono categórico, sin matices, del terceto que la encierra. Para Cervantes, la distinción entre sátira legítima e ilegítima fue más fácil de sostener en teoría que en la práctica ${ }^{8}$; de ahí sus escrúpulos con respecto al género, en los que se entremezclan ingredientes religiosos, estéticos y político-sociales. Dejo aparte, por evidentes, los escrúpulos legales, que se reflejan en la pena de destierro impuesta a Clodio en Persiles; en el retrato de este personaje, y en su fin ejemplar, se resume buena parte de los recelos que examino a continuación ${ }^{9}$. Consideremos primero los escrúpulos de tipo religioso, que tienen su origen en el precepto evangélico: "Reprehended a tal con el espíritu de mansedumbre, considerándote a ti mismo, porque tú no seas también tentado" (Gálatas, 6, 1). Precepto muy pertinente a los españoles de aquella época debido a su tendencia a identificar la sátira con la murmuración o la áspera reprehensión de vicios y necedades comunes. En las antiguas ediciones de Quevedo, estas tachas, y los oficios, estados y tipos a que corresponden, van catalogadas en las apostillas al margen: taberneros, hipócritas, ricos, pobres, discretos, necios, negociantes, reyes, eclesiásticos, etc. Como en la danza de la muerte medieval, los siete vicios capitales desfilan delante del satírico, plasmados en defectos estamentales, para recibir su merecida reprobación. Así, pues, su oficio coincide en parte con "el que tienen oy los predicadores" (Garvallo). Sin embargo, considerada como un sermón, la sátira tiene mucho de insólito $^{10}$; poderosos impulsos inherentes a su esencia la llevan a su-

Rín en RABM, 17 (1907), pp. 1 ss., y 433 ss., y el segundo es citado por el mismo erudito en su edición del Viaje del Parnaso, Madrid, 1935, p. lxviii. Los poetas plebeyos ridiculizados en ambos poemas son de la misma estirpe que los poetastros derrotados en la batalla de los libros del poema cervantino.

${ }^{7}$ Monique Joly, La bourle et son interprétation, Atelier National de Reproduction des Thèses, Université de Lille III, Lille, 1982.

${ }^{8}$ Cuando hace decir a Tirsi en el libro cuarto de La Galatea: "Abrásense las obras de los heroicos poetas, porque con sus sátiras y versos los vicios reprehenden y vituperan [...]" parece condenar el género en conjunto sin concesiones a la sátira legítima (eds. R. Schevill y A. Bonilla, 2 ts., Madrid, 1914, t. 2, p. 65).

${ }^{9}$ Los contextos relevantes se hallan en Persiles I, 14 y II, 2, 5, 7, 8.

${ }^{10}$ Evidentemente, los hombres de aquella época reconocían una diferen- 
blevarse contra el precepto de San Pablo, planteando así un posible dilema de conciencia. Por supuesto, es un dilema que preocupa a unos escritores más que a otros y que no sólo preocupa a escritores cristianos. Cervantes lo tomó muy en serio, especialmente en el último decenio de su existencia, cuando su edad no estaba ya para burlarse de la otra vida. En la aprobación que puso el licenciado Márquez Torres a la Segunda parte del Quijote, alaba a Cervantes por haber guardado "con tanta cordura las leyes de reprehensión cristiana", y en el curso del elogio, se hace eco de la admiración que los humanistas sentían por Horacio como poeta satírico que supo corregir vicios con amenidad y tacto ${ }^{11}$. Para Márquez Torres, Cervantes es un Horacio cristiano. La comparación implícita es acertada; de los satíricos de la Antigüedad, fue Horacio quien sintió más agudamente el susodicho dilema moral; su célebre urbanidad es un medio práctico de resolverlo.

El segundo escrúpulo es de orden estético. Para Cervantes, un tono didáctico muy acusado - por ejemplo, el del Guzmán de Alfarache - no conviene a una obra cómica de estilo llano y tono festivo, cuyo fin principal es incitar a risa a los lectores (véase el prólogo a la Primera parte del Quijote). Sin embargo, el didactismo es inherente a la sátira, que linda con el género cómico. ¿Hasta qué punto, pues, debe admitirse en una novela como El coloquio de los perros, novela que está a caballo entre los dos géneros? Pasemos al tercer escrúpulo, también de carácter estético: la preocu-

cia de métodos entre los dos géneros, atribuyéndoles fines comunes. Con respecto a Horacio, Villén de Biedma dice lo siguiente: "Sátiras son las que escribió y Sermones los llamó; aunque en rigor no lo sean; porque si el fin de ambas cosas no es diferente, queriendo hacerse un mismo efecto, el proceder no es el mismo, siendo las reprehensiones de las Sátiras dichas por donaire, procurando la risa lasciva y el aplauso de los oyentes, y los Sermones para hacer sus culpas al que las tiene",; cf. $Q$. Horacio Flacco ... sus obras con la declaración magistral en lengua castellana por el doctor Villén de Biedma, Granada, 1599, p. $170 \mathrm{v}^{\circ}$.

${ }^{11}$ Sin mencionar a Horacio expresamente, el pasaje contiene un eco evidente de su omne tulit punctum qui miscuit utile dulci y se anticipa muy concretamente a los términos en que Cascales pondera los méritos del poeta latino. Cf. Cascales, Tablas poéticas, ed. cit., p. 180: "Es artificio suyo no ensangrentar la lanza contra uno, sino tratando de una cosa, picar a éste y al otro de camino [...]", y más por el estilo. Si, como afirman algunos, fue el propio Cervantes el que redactó la aprobación firmada por Márquez Torres, esto restaría valor al elogio como juicio objetivo para conferirle valor de testimonio personal. Véase E. L. Rrvers, "On the prefatory pages of Don Quixote Part II," MLN, 75 (1960), 214-221. 
pación de Cervantes por el tono ejemplar de la literatura. Por ser archiconocida, me ahorro ejemplos; como luego veremos, sus repercusiones prácticas son profundas. Y por último, los escrúpulos político-sociales. En el entremés La elección de los alcaldes de Daganzo, un personaje amonesta a un sacristán irreverente con este precepto, que rezuma un espíritu profundamente antidemocrático:

Deja a los que gobiernan, que ellos saben lo que han de hacer mejor que no nosotros; si fueren malos, ruega por su enmienda; si buenos, porque Dios no nos los quite ${ }^{12}$.

La misma idea se repite en distintas formas en otros contextos cervantinos. Podemos especular sobre los móviles latentes en ella - ¿deferencia o resignación? - pero no podemos dudar del abstencionismo que pone de manifiesto.

Pelorson sostiene la tesis de que la sátira se fue politizando en las épocas de Felipe III y IV, tras un periodo de apolitización en el reinado de Felipe $\mathrm{II}^{13}$. El proceso llegaría a su punto culminante en "La hora de todos" (terminada en 1636) de Quevedo. Los tres escritores que, según Pelorson, mejor representan el despertar de la conciencia política a principios del siglo xvi son Alemán, Cervantes y Suárez de Figueroa. Este juicio corre el riesgo de dar una idea equivocada de la actitud de Cervantes ante cuestiones políticas. Como observador inteligente del mundo social y político que lo rodeaba, no podía menos de tener opiniones, incluso opiniones críticas, sobre lo que pasaba en él. Sin embargo, por principio, suele negarse a expresar estas ideas abiertamente, excepto cuando el juicio emitido tiene pocas posibilidades de herir sensibilidades, por ejemplo, por coincidir con un consenso de opinión nacional. A fortiori, adopta la misma reticencia en cuanto a la controversia religiosa. En cambio, se permite una mayor libertad al fallar sobre la corrupción administrativa a nivel municipal (ejemplo, el ayuntamiento de Sevilla) o sobre las arbitrariedades del sistema judicial (Sevilla, de nuevo).

12 En el tomo 4 de las Comedias y entremeses, eds. R. Schevill y A. Bonilla, Madrid, 1918, p. 56; la misma idea se expresa en El laberinto de amor, ed. cit., t. 2, p. 265, y en El coloquio de los perros, p. 336.

${ }^{13}$ Jean-Marc Pelorson, "La politisation de la satire sous Philippe III et Philippe IV', en La contestation de la société dans la littérature espagnole du sièele d'or: travaux de l'Université de Toulouse-le-Mirail, Université de Toulouse-le-Mirail, Toulouse, 1981, pp. 95-107. 
Voy a dar un ejemplo concreto de esta actitud, ejemplo pertinente al argumento de Pelorson, ya que supone una comparación directa entre Cervantes, Alemán y Suárez de Figueroa. Tanto en la primera parte (1599) del Guzmán de Alfarache (I, ii, 9) como en el Alivio 5 de El Pasagero de Suárez de Figueroa (1617) se encuentran pasajes en que se lamenta la decadencia de las armas españolas: debida, según Alemán, a la gestión interesada de los privados del rey, y según Suárez de Figueroa, a la escasa participación de los hidalgos y nobles en las empresas militares. Ni Alemán ni el atrabiliario Suárez de Figueroa se quedan cortos al formular sus críticas. La invectiva de este último, dirigida a un cortesano imaginario, contiene lindezas como las siguientes:

Ídolo de criados, de súbditos a quienes oprimes, a quien desuellas ¿cuánto más apacible es para ti la suavidad de la holanda que la aspereza del arnés, la blandura de la cama que la dureza del suelo, la dulzura de la conserva que el amargor de la achicoria? ¿Tú armado por estío? ¿'Tú en campaña por invierno? ${ }^{14}$

Pues bien, es evidente que Cervantes comparte las opiniones de ambos escritores. Hace decir al galeote Ginés de Pasamonte: "Allí [en las galeras] tendré lugar de acabar mi libro, que me quedan muchas cosas que decir, y en las galeras de España hay más sosiego de aquel que sería menester"'15. Al principio de la Segunda parte de la misma novela, en medio de un disparatado elogio a los caballeros andantes de antaño, Don Quijote desliza el siguiente comentario:

Los más de los caballeros que agora se usan, antes les crujen los damascos, los brocados y otras ricas telas de que se visten, que la malla con que se arman; ya no hay caballero que duerma en los campos, sujeto al rigor del cielo, armado de todas armas desde los pies a la cabeza $[\ldots]^{16}$.

Salta a la vista la coincidencia entre este pasaje y el ya citado de Suárez de Figueroa. Las mismas insinuaciones se repiten más tarde en la Segunda parte (capítulo 17), y aparecen expresadas también por un personaje secundario de la comedia $E l$ gallardo español ${ }^{17}$. Así que podemos conjeturar que para sus adentros, o

${ }^{14}$ Edición de F. Ronkíguez Marín, Madrid, 1913, p. 189.

${ }^{15}$ Don Quijote, I, 21, ed. cit., t. 1, p. 272.

${ }^{16}$ Don Quijote, II, I, ed. cit., t. 2, p. 48.

17 Comedias y entremeses, ed. cit., t. 1, p. 69. 
en charla privada con sus amigos, Cervantes pensaría o hablaría de la misma manera que Alemán o Suárez de Figueroa. Pero al estampar estas opiniones en letras de molde, se sirve de insinuaciones veladas, apartes llenos de intención para los entendidos, dichos que no sabemos si tomar en serio o en broma. ¡Cuántas conjeturas descabelladas han podido fabricarse en torno a la ideología de Cervantes precisamente debido a esa tendencia suya a dejar entrever lo que piensa, en vez de declararlo! 18

De todo lo anterior se deduce que el tratamiento de la sátira en Cervantes no obedece, como muchas veces se ha pretendido, a motivos ideológicos (disidencia erasmista, etcétera), sino a motivos "de oficio". Éstos le han dado un sesgo distintivo y personal. Si comparamos El licenciado Vidriera y El coloquio de los perros - ejemplos fundamentales de la sátira cervantina de tendencia socio-moral - con las obras satíricas de Góngora y Quevedo, observamós en seguida que faltan en las dos novelas cervantinas los temas consagrados (según Hodgart) de la tradición satírica: la mujer (o la sexualidad), la política, la religión ${ }^{19}$. Ahí no hallamos nada parecido a los chistes de tono subido de los dos escritores coetáneos sobre viudas verdes, maridos consentidos, clérigos mujeriegos y dadivosos, sodomitas, cortesanas, pedigüeñas, etc., nada parecido a la "obsesión excreminticia" de Quevedo, que más que rasgo peculiar, es reflejo de la acusada tendencia escatológica del humor de la época; nada parecido a la repugnante tendencia quevediana a reducir a la mujer a sus funciones biológicas "vergonzosas"; nada parecido a los desenfadados insultos personales que se entrecruzaron entre los dos poetas enemistados; nada parecido a la personalidad cínica y plebeya que Góngora adopta como postura satírica en sus Letrillas, cuyos irreverentes refranes y estribillos expresan algo así como la filosofía de Lazarillo de Tormes, nada parecido, finalmente, a la audaz intromisión de Quevedo en la política internacional y controversias religiosas de su época. Precisamente por su cualidad sobria y recatada, la sátira cervan-

${ }^{18}$ No sólo teorías descabelladas. A lo mejor J. A. Maravall, Utopía y contrautopia en el "Quijote", Pico Sacro, Santiago de Compostela, 1976, tiene su parte de razón al sostener que el Quijote debe interpretarse como un ataque a residuos de pensamiento utópico que persistían en la mentalidad política de la época. Sin embargo, lo esencial para mí es que esta tesis no se funda en evidencia transparente, sino en la comparación sistemática entre lo que Cervantes deja entrever y lo que otros dicen claramente.

19 Véase Matthew Hodgart, Satire, Weindelfeld \& Nicolson, London, 1969 , caps. 2 y 3 
tina de tendencia socio-moral resulta a menudo menos divertida que la de los dos escritores coetáneos. Echamos de menos su chispeante irreverencia.

Se perciben otros vacíos quizás menos evidentes que los mencionados. Habida cuenta de la restricción impuesta por el eje narrativo de El coloquio, autobiografía de un perro basada en los recuerdos que guarda de sus sucesivos amos, la novela cubre una gama de oficios relativamente limitada: ciertos grupos parásitos y delincuentes; algunos chiflados y obsesivos; algunos pedantes y poetastros. Las críticas más severas se reservan para la primera categoría: jiferos, gitanos, moriscos, brujas, etc. El hecho es significativo y refleja uno de los criterios que gobiernan la sátira en la novela: el buen sentido moral del ciudadano honrado que se escandaliza ante la subversión marginal de valores civilizados "evidentes". La actitud es algo distinta del escepticismo radical de Quevedo, fruto de un estoicismo desengañado y prejuicios nobiliarios; desde esta perspectiva, se contempla toda la vida social como una amarga farsa regida por la codicia y las falsas apariencias. $\mathrm{Y}$ en cuanto al honor y la jerarquía falsificados - tema obsesivo en Quevedo, que abarca figuras y tópicos como el caballero chanflón, el converso, el dinero que todo lo corrompe- a Cervantes sólo le preocupa un aspecto restringido del mismo: las pretensiones sociales de cristianos viejos de clase villana. Le preocupan mucho más los conflictos violentos que resultan del honor ultrajado y el desajuste entre la opinión social y la verdadera virtud ${ }^{20}$.

Todo ello demuestra una tendencia a la moderación en Cervantes que aleja sus obras satíricas de ese afán, tan característico de muchos grandes satíricos, de extremar la indignación y buscar una retórica chocante para comunicársela al lector en estado candente: tono chocarrero e insultante, vituperación desenfrenada, obscenidad, deformación grotesca de los tipos ridiculizados, desaforados vuelos de la fantasía o del juego verbal que desenmascaran abusos disfrazados por las apariencias convencionales.

Para ilustrar concretamente cómo suele atenuar Cervantes la aspereza satírica voy a seguir refiriéndome a las dos novelas mencionadas, y por ende, a la sátira cervantina de tendencia sociomoral. Sin unas salvedades previas, mis conclusiones no pueden

20 De estos dos problemas, el primero apenas si aparece en las dos novelas satíricas, aunque se reitera en el Persiles (p. ej., el episodio de Ortel Banedre, III, 6-7) y en la segunda parte del Quijote (p. ej., el episodio de los rebuznadores, cap. 27); el segundo es un tema importante del Coloquio (véase la conclusión). 
aplicarse a la sátira de tendencia literaria: por ejemplo, los prólogos al Quijote, los diálogos críticos de la novela, el Viaje del Parnaso, así como varios contextos paródicos o irónicos de constitución polémica menos formal. Por motivos particulares, la Primera parte del Quijote - ejemplo por antonomasia de ese tipo de sátira - ostenta un vigor polémico que desentona en cierto modo con la mencionada moderación horaciana; sospecho que los escrúpulos expresados en el Coloquio (probablemente compuesto poco después de la publicación de la Primera parte) son fruto de escarmiento. Además, la sátira literaria cervantina posee una modalidad propia: es salada, alegre, traviesa, chispeante, fantástica. Sin pretender que pertenezcan a compartimientos estancos, me propongo, por de pronto, tratar las dos modalidades como distintas. Antes de seguir adelante, debo aclarar mi concepción del género, que se basa en los criterios de la época. Los modelos que lo definían concretamente o eran 'exagemáticos' - el autor (por ejemplo, Horacio, Juvenal) habla en primera persona- o se aproximaban a este paradigma - diálogos imaginarios (de Luciano, Erasmo, Quevedo) en que un personaje perspicaz se encarga de la censura, empleando una retórica más o menos convencional: ironía socrática, invenctiva, etc. Por lo tanto, las aventuras de Don Quijote, que para nosotros tienen un indudable impacto satírico, quizás no lo tuvieran para los coetáneos de Cervantes, puesto que logran su efecto demoledor por medios indirectos más que por la censura explícita. Además, en aquella época se distinguían los objetivos de la sátira de los de la comedia: a aquélla le tocaba censurar costumbres, y a ésta, representarlas bajo un aspecto más inocuo y risible. Como Cervantes insiste en el carácter risible del Quijote, a lo mejor no disintió del rótulo de "comedia" que Avellaneda le pone ${ }^{21}$.

El objeto característico de la sátira socio-moral de Cervantes es la naturaleza humana depravada por el pecado, rebelde a la convivencia social, tercamente entrometida, etc., y su retórica habitual la constituyen la diatriba elegante, el aforismo caústico, la reconvención razonada. Aquí Berganza las emprende con varios tipos de vagos y maleantes:

Que esto del ganar de comer holgando tiene muchos aficionados y

${ }^{21}$ El prólogo al Quijote en Avellaneda empieza así: "Como casi es comedia toda la "Historia de Don Quijote de la Mancha".. ." Cito por la edición Espasa-Calpe, Madrid, 1958. 
golosos: por esto hay tantos titereros en España; tantos que muestran retablos; tantos que venden alfileres y coplas, que todo su caudal, aunque le vendiesen todo, no llega a poderse sustentar un día; $\mathrm{y}$, con esto, los unos y los otros no salen de los bodegones y tabernas en todo el año; por do me doy a entender que de otra parte que de la de sus oficios sale la corriente de sus borracheras. Toda esta gente es vagamunda, inútil y sin provecho; esponjas del vino y gorgojos del pan (p. 282).

El estilo contundente trae a la memoria la reprehensión dirigida a Don Quijote por el canónigo de Toledo (I, 49), la taxonomía despreciativa con que Cervantes aplasta al capellán del Duque (II, 31), varios dichos de Vidriera. El efecto abrumador de estos 'tantos' y los epítetos degradantes logran el efecto satírico. Aparte de esto, tales pasajes tienen mucho en común con otros en que se condenan vicios generales o individuales en términos más moderados: por ejemplo, los consejos de Periandro al vengativo Ortel Banedre (Persiles III, 7).

Por ser negativa, la visión proporcionada por esta modalidad satírica exige el complemento de otra visión que supla los matices que faltan. El áspero juicio de Berganza sobre los vagos y maleantes no toma en cuenta que aun esta escoria humana puede tener, en casos individuales, cualidades que la rediman, ni que cabe contemplarla bajo una luz risueña como cantera de tontería, burlas, y chistes. La jovial y pintoresca personalidad de Maese Pedro - titerero y vagamundo, luego directamente afectado por la condenación de Berganza - es un ejemplo dramático del cambio de perspectiva que resulta de la transición de la órbita satírica a la cómica. Otro tanto puede decirse de los gitanos y moriscos, severamente condenados en El coloquio y retratados de modo mucho más benigno en La gitanilla y la Segunda parte del Quijote. La clave principal de este cambio la encontramos en el carácter de Fray Antonio, el gracioso de El rufián dichoso, fiel compañero del héroe en sus mocedades sevillanas y en su carrera monástica. En la economía de esta comedia de santos, este personaje desempeña una función ejemplar (entre otras): la de representar en forma humorística el mundo pecaminoso cuyas manchas aún subsisten en el alma asceta de Fray Cruz. Para éste, los chistes del gracioso, alusivos al buen tiempo pasado del hampa sevillana, son motivo de dolorosos recuerdos y merecen reprehensión; para otros (el Prior, el inquisidor Tello, el propio Fray Antonio), son manantial de humor sin intención genuinamente maliciosa y por eso me- 
recen una acogida más indulgente ${ }^{22}$. El punto de vista de estos últimos coincide con el del dramaturgo y el espectador, para quienes el gracioso sirve de puente entre las sublimes alturas de la santidad y el mundo cotidiano. Así, pues, la comedia humaniza los objetos de la reprehensión moral, los convierte en materia de risa inofensiva, y les inocula su vacuna peculiar: la tontería absurda, el espíritu lúdico del chiste, para inocularnos a nosotros contra su efecto contagioso. Los dos enfoques son diferentes, pero no contradictorios.

Ahora bien, dentro del ámbito de la sátira cervantina, no sólo coexisten sino que se confunden. Al hablar de la cofradía de Monipodio, Berganza dice lo siguiente: "Quererte yo contar ahora lo que allí se trató, la cena que cenaron, las peleas que se contaron, los hurtos que se refirieron, las damas que de su trato se calificaron y las que se reprobaron, las alabanzas que los unos a los otros se dieron [...] sería meterme en un laberinto donde no me fuese posible salir cuando quisiese'" (pp. 272-273). Aquí se pone de relieve la vis cómica que anhela recrearse en la pintura morosa de los rasgos de una fauna pintoresca. Y en muchas ocasiones sucumbe a la tentación. Por ejemplo, en cierto pasaje de El licenciado Vidriera, el protagonista ofrece una brillante caricatura de un poeta vanidoso (pp. 47-48). Este personaje - pura creación de la musa satírica - debe ser comparado con los dos poetas retratados por Berganza; vemos cómo un haz de manierismos estereotipados se convierte en personalidades diferenciadas, humanas, ingenuamente disparatadas -creaciones propias de la musa cómica. El primero de estos poetas, a pesar de sus ridículas manías, desmiente el cinismo del refrán "Más da el duro que el desnudo", demostrando así su parentesco con el escudero de Lazarillo; ante el ignominioso fracaso de su comedia, reacciona con una ufanía digna de Don Quijote (pp. 319-327). Los ejemplos del predicador Berganza casi desentonan con la aspereza del sermón.

El mismo efecto suavizante se nota en la personalidad de los portavoces de Cervantes. Por estrafalarios que sean en algunos aspectos de su comportamiento, poseen gravedad intelectual y moral en sus "lúcidos intervalos", y su sabiduría ha sido enriquecida por los viajes y los libros. El tema simbólico de la vida como peregrinación educativa está implícito en sus andanzas. De este modo, la sátira cervantina se nos presenta como el aspecto crítico y desengañado de una meditación grave sobre la vida moral del

22 Véase Comedias y entremeses, ed. cit., t. 2, pp. 57, 63-65. 
hombre y una sucesión de casos ejemplares que ilustran su naturaleza. Esta meditación no sólo consiste en pensamiento sino también en experiencia vivida: así, los valores sustentados por los perros El coloquio - humildad, caridad y fe cristianas; conformarse cada uno con su estado, etc. - toman cuerpo en la forma del diálogo y en los avatares de Berganza. Y, desde luego, los casos que comentan son peripecias de una autobiografía novelesca. Todo ello hace que nuestra atención, en última instancia, no se centre en el espectáculo de vicios y disparates sociales sino en la forja de un destino individual, en que aquéllos repercuten como lección provechosa o fenómeno contemplado desde fuera. En El licenciado Vidriera se hace patente, e incluso se plasma en división formal, la divergencia entre estas dos perspectivas.

Gracias a este enfoque, el mal se considera como un dilema existencial en que el primero en verse comprometido es el mismo protagonista de la fábula. La diferencia entre esta actitud "filosófica" y una actitud satírica se pone de manifiesto comparando dos pasajes: las meditaciones casi prefreudianas de Cipión sobre la agresión infantil, considerada como prueba del pecado original, y las amargas reflexiones de Guzmán de Alfarache con las que remata su ataque a la obsesión española por el honor y las falsas apariencias. Cipión dice:

Que el hacer y decir mal lo heredamos de nuestros primeros padres y lo mamamos en la leche. Véese claro en que apenas ha sacado el niño del brazo de las fajas, cuando levanta la mano con muestras de querer vengarse de quien, a su parecer, le ofende; y casi la primera palabra articulada que habla es llamar puta a su ama o a su madre (p. 240).

\section{Y Guzmán:}

Todo anda revuelto, todo apriesa, todo marañado. No hallarás hombre con hombre; todos vivimos en asechanza los unos de los otros, como el gato para el ratón o la araña para la culebra, que hallándola descuidada, se deja colgar de un hilo y, asiéndola de la cerviz, la aprieta fuertemente, no apartándose della hasta que con su ponzoña la mata ${ }^{23}$.

Leídos así, los dos pasajes parecen afines, pero en realidad,

${ }^{23}$ Guzmán de Alfarache I, ii, 4, ed. S. Gili Gaya, 5 ts., Espasa-Calpe, Madrid, 1969 , t. 2, p. 54 . 
sirven de remate a argumentos distintos. La orientación del segundo es objetiva, pese a la primera persona del plural; Guzmán ha venido censurando vicios que él todavía no comparte. En cambio, Cipión lamenta una agresividad cuya muestra inmediata es la murmuración en que él y su compañero reinciden una y otra vez; el censor se acusa a sí mismo junto con los demás.

Estas reflexiones, en cierto modo el eje del diálogo, proporcionan una lección de humildad que afecta profundamente su estructura y sus principios dinámicos. Cervantes ha operado un cambio sorprendente en el esquema convencional del diálogo lucianesco/erasmista, según el cual un interlocutor "activo" - discreto, perspicaz, etc. - se opone a otro interlocutor (o interlocutores) "pasivo" - curioso pero inexperto, ingenuo, equivocado. No sólo ha complicado el esquema, combinándolo con el de una autobiografía picaresca, sino que lo ha invertido, confiando al interlocutor impulsivo y locuaz (Berganza) el papel "activo" y a su juicioso compañero el papel "pasivo". El oficio principal de Cipión consiste en criticar y moderar los excesos del relato de Berganza, mayormente su propensión a murmurar. Pero esta división de funciones fluctúa; de vez en cuando, Cipión olvida sus propios preceptos y debe escuchar las reconvenciones de su colega. Todo el humor y vitalidad del diálogo emanan de los altercados familiares entre los dos perros, que nos recuerdan continuamente los de Don Quijote y Sancho: amonestaciones contra la prolijidad o la murmuración que desinflan irónicamente una perorata apasionada; exasperación cómica de uno u otro interlocutor cuando el compañero reincide por enésima vez en la misma falta. No se trata de la supuesta predilección cervantina por diálogos o cuentos "abiertos" en que nunca se llega a conclusiones definitivas. Éstas no escasean en El coloquio. Nos enfrentamos con algo distinto: un hábito de moderación intelectual que ya puede observarse en La Galatea y que consiste en plantear un argumento moral en forma dialéctica. A una posición extremada se le opone una réplica moderada (debate sobre el amor entre Lenio y Tirsi), o se busca juiciosamente el término medio entre posiciones exageradas (papel característico del cura Pero Pérez en el Quijote), o se contrastan dos extremos (Don Quijote y Sancho), cuyo término medio debe ser buscado por el discreto lector. El siguiente fragmento de El coloquio se refiere al mercader sevillano, tercer amo de Berganza:

Berganza: Ambición es, pero ambición generosa, la de aquel que pretende mejorar su estado sin perjuicio de tercero. 
Cipión: Pocas o ninguna vez se cumple con la ambición, que no sea con daño de tercero.

Berganza: Ya hemos dicho que no hemos de murmurar.

Cipión: Sí, que yo no murmuro de nadie (p. 239).

Autojustificación hipócrita que es luego desmentida por Berganza. Ahora bien, la técnica satírica quevediana consiste en dar por sentada la identificación de la figura del mercader con la rapiña y la ambición hipócritamente disfrazadas ${ }^{24}$. En cambio, en el fragmento citado, es precisamente esta premisa la que se pone en tela de juicio, y además, se duda de la buena fe de quien duda sistemáticamente de la de sus prójimos. He aquí en miniatura el espíritu de autocrítica de la novela y el equilibrio racional que supone.

El coloquio se ha prestado a interpretaciones muy divergentes, y ello se debe en parte a que Cervantes ha complicado profundamente la referencia habitual de la sátira de su época, convirtiendo las especies (hipócrita, rico, médico, etc.) en géneros y los géneros en universales. Buen ejemplo de ello nos lo proporciona el episodio de los pastores-lobos, en que se pone al descubierto el cómo y porqué de la transformación. Al hablar del matadero de Sevilla, Berganza dice: "Los dueños se encomiendan a esta buena gente que he dicho, no para que no les hurten (que esto es imposible), sino para que se moderen en las tajadas y socaliñas que hacen en las reses muertas"' (p. 217). Insinúa a continuación: “No hay ninguno que no tenga su ángel de guarda en la plaza de San Francisco [sede del Cabildo y de la Audiencia], granjeado con lomos y lenguas de vaca". Cipión pone fin a la invectiva casi inmediatamente, amonestando a Berganza a no ser prolijo. Pero éste vuelve a la carga unas páginas después, envolviendo el caso del matadero sevillano en una anécdota aparentemente distinta, pero cargada de alusiones al episodio anterior. Se trata de la narración de sus esfuerzos frustrados por defender un rebaño de los ataques de un lobo misterioso que lo va devorando poco a poco. $\mathrm{He}$ aquí el desenlace del relato: "Pasméme, quedé suspenso cuando vi que los pastores eran los lobos, y que despedazaban el ganado

${ }^{24}$ El demonio de "El alguacil alguacilado" dice de los mercaderes: "Manjar es que nos tiene ya empalagados a los diablos y ahítos, y aun los vomitamos. Vienen allá a millares, condenándose en castellano y en guarismo [...]", etc. La pirotecnia virulenta del pasaje se basa en la atribución a esa gente de una codicia infernal, indigesta para los propios diablos; Quevedo: Los Sueños, ed. J. Cejador y Frauca, 2 ts., Madrid, 1954, t. 1, p. 77. 
los mismos que le habían de guardar. Al punto hacían saber a su amo la presa del lobo, dábanle el pellejo y parte de la carne, y comíanse ellos lo más y lo mejor"' (p. 232). Las semejanzas entre los dos pasajes son significativas. Sin embargo, sería muy equivocado hacer de ellas una clave esotérica para descifrar el cuento de Berganza, ya que es evidentemente deliberado el intento de suscitar reflexiones que trasciendan abusos particulares y abarquen la convivencia social en conjunto: el abuso de la confianza, cemento de la sociedad, sin el cual ésta no puede sostenerse. Evidentemente, todo el poder sugerente e inquietante del cuento estriba en el hecho de que no se nos dice, ni nos importa saber, quiénes son estos pastores ni qué grupo representan. Para convertir el caso concreto en símbolo universal Cervantes ha echado mano de la tradición esópica, fuente de varios lances de la novela; aunque el cuento de Berganza tiene un aspecto verosímil y no alegórico, está emparentado con apólogos tradicionales que tratan de lobos, perros, pastores y ovejas, y apuntan a una moraleja parecida.

El supuesto pesimismo de El licenciado Vidriera, como de El coloquio, ha sido excesivamente exagerado por la crítica cervantina, que ha percibido el simbolismo más siniestro en la locura del héroe: encarnación del pecado faustiano, del desengaño contrarreformista, o del espíritu malévolo de los cínicos antiguos. Estas interpretaciones sombrías obedecen al deseo de encontrar una relación (de desquite, castigo, etc.) entre los dichos de Vidriera y su engaste biográfico; reflejan también una valoración anacrónica de la mordacidad que revelan. Los dichos se hallan encuadrados por dos pasajes - uno, el preámbulo, y otro, la conclusión - que insisten en los síntomas extravagantes de la manía melancólica de Vidriera y la acercan al diagnóstico corriente en los tratados médicos de la época. Esto implica que, más que como símbolo de una inteligencia maligna, el loco Vidriera debe ser considerado un curioso prodigio psicológico. Como tal lo consideran cuantos personajes lo conocen, incluso las muchedumbres que le siguen por doquier, tratándole como un truhán de las calles y solicitando sus agudezas, aun a sabiendas del resultado probable. Todo ello resta importancia al contenido e impacto crítico de sus dichos y realza la de su forma.

Así, la sección central de la novela es un muestrario de agudeza con tendencias - sólo tendencias - satíricas. A primera vista, parece desplegar un panorama parecido al de los Sueños: la justicia venal y sus funcionarios; los médicos y sus adláteres; las "figu- 
ras" de la corte (viejos que se tiñen la barba, diestros científicos...); los bajos oficios (sastres, pasteleros... ${ }^{25}$. Pero si tratamos de apurar el paralelo, se nos imponen las diferencias. Lo que confiere a los Sueños su aspecto de auténtico panorama satírico es el encadenamiento de las censuras para lograr un efecto pictórico, abrumador y coherente; la coherencia tiene una faceta ideológica, presentándose los objetos criticados como mónadas de un cosmos unido por un rasgo común: por ejemplo, la hipocresía universal. Los dichos de Vidriera, casuales e inconexos, carecen de tal homogeneidad. La verdadera filiación de la novela cervantina debe buscarse en la tradición apotegmática, y muy particularmente, en colecciones como las de Melchor de Santa Cruz, Timoneda, Pinedo y Rufo, que ostentan el mismo tipo de agudeza cortesana.

El carácter específico de esta conexión puede comprobarse mediante una comparación de los dichos de Vidriera con los de Rufo. Dejo a un lado la cuestión de si Cervantes leyó o no Las seiscientas apotegmas para señalar algo que considero más importante: la amplia difusión de este tipo de conceptismo en la cultura (no sólo escrita) de la época. Las dos colecciones se asemejan primero en la cualidad improvisada de sus apotegmas, sin la cual, dice Rufo, sus dichos son como oro sin hechura para realzarlo ${ }^{26}$. Se parecen, muy evidentemente, en su forma anecdótica y circunstancial. Contienen las mismas especies apotegmáticas: chistes, aforismos morales, elogios, observaciones "costumbristas". Desde luego, hay diferencias: la colección cervantina tiene una proporción más elevada de censuras de oficios, o chistes que las implican; los dichos de Rufo se refieren frecuentemente a individuos o circunstancias particulares. Pero éstas son diferencias relativas. Lo esencial es que los dos "decidores de repente" demuestran el mismo tipo de mordacidad, la misma postura moralizante, los mismos juegos conceptistas.

Habida cuenta de la relatividad de tal juicio ${ }^{27}$, el humor de la época muestra una propensión muy acusada a expresarse en chistes "agresivos"' (injuriosos, obscenos, escatológicos) y en reflexiones cáusticas — válvula de escape para los sentimientos je-

${ }^{25}$ Véanse las clasificaciones de la temática quevediana en la valiosa tesis de Arellano Ayuso, Poesía satírico-burlesca de Quevedo, Universidad de Navarra, Pamplona, 1984, pp. 48 y 85.

${ }^{26}$ Véase Las seiscientas apotegmas y otras obras en verso, ed. Alberto Blecua, Madrid, 1972, apotegma número 307.

${ }^{27}$ A este respecto, véanse las juiciosas advertencias de MoniQue Joly, op. cit., pp. 3 ss. 
rárquicos, morales y de conveniencia social subyacentes. Rufo presenta una imagen de sí mismo bien definida: un caballero recto, afable y urbano, de fe católica sincera, principios morales serios y gustos cultivados. Pues bien, este hombre refinado no ve inconveniente alguno en dirigir chistes mordaces y censuras aplastantes a sus prójimos, incluso a gente desconocida que topa por las calles, aludiendo libremente a sus tachas físicas, inmoralidad sexual, etc. Esta desenvolutra poco o nada difiere del comportamiento de Vidriera. Para rechazar el envite deshonesto de unas rameras Rufo dice: "No me quiero ir al infierno en mulas de alquiler"' (p. 179). Vidriera enjuicia unas rameras en estilo parecido, calificándolas de "bagajes del ejército de Satanás, que estaban alojados en el mesón del infierno" (pp. 40-41). Los chistes y apodos de Vidriera a propósito de viejos que se tiñen la barba (p. 67) pueden compararse con lo siguiente, dirigido por Rufo a una vieja fea y arrebolada (es decir, muy afeitada): "Arreboles a la noche, y a la mañana sin sol" (p. 317), o con varios de los apodos en la antología de Santa Cruz: por ejemplo, "A uno que tenía muy poco pelo en la barba, dijo [un canónigo de Toledo] que parecía lugar despoblado en tiempo de pestilencia" 28 .

Se ha intentado hacer una distinción entre los chistes mordaces de Vidriera y los chistes anodinos, sin intención maliciosa ${ }^{29}$. En vista de lo arriba citado, la distinción me parece muy dudosa. Los equívocos aparentemente mordaces que confunden "vecinas" y "alcahuetas", juegan con el doble sentido de "cuento" tratándose de genoveses, o dan un matiz siniestro a la terminación "sana" en "cortesana", son lugares comunes del humor de la épo" ca. Puestos en boca de un gracioso de una comedia de Lope de Vega tendrían un impacto crítico relativamente reducido. Desde luego, encontramos los mismos chistes en los Sueños, y lo que allí les confiere un efecto satírico es el contexto en que aparecen - "la cadena abrumadora" - y su tónica dominante. Así, la línea divisoria entre el humor de la época y la sátira propiamente dicha es difícil de fijar con exactitud. Difícil, pero no imposible. Todo es cuestión de contexto e intención dominantes.

Examinados a la luz de la definición de la agudeza que ofrece Gracián en su Agudeza y arte de ingenio, Discurso 4, los apotegmas p. 124 .

${ }^{28}$ Melchor de Santa Cruz, Floresta española, Espasa-Calpe, Madrid,

${ }^{29}$ Cf. Armand E. Singer, 'Cervantes' Licenciado Vidriera: its form and substance", West Virginia University Philological Papers, 7 (1951), 13-31; véase también el artículo citado de RILEY, p. 190. 
de Rufo trazan 'líneas de ponderación y sutileza' entre las contingencias casuales de una situación para hallar en ellas una conexión insospechada, ingeniosa y causante de admiración. Estas correspondencias pueden fundarse en analogías, equívocos, argumentos sofísticos, rimas, asonancias, lugares comunes, versos del Romancero, o en otros recursos. Ya hemos visto algunos ejemplos. Examinemos otros en que el propósito mordaz o moralizante está matizado fuertemente, e incluso dominado, por el estético. Muy del gusto de Rufo y Vidiera son censuras que ponderan lo desmesurado de un vicio mediante hipérboles o analogías sutilmente elaboradas, argumentos paradójicos, o breves periodos retóricos que hacen alarde de ingeniosidad mediante elegantes simetrías y antítesis, conceptos encadenados, etc. Vidriera reprehende así a un mozo de mulas: "La honra del amo descubre la del criado; según esto, mira a quién sirves, y verás cuán honrado eres: mozos sois vosotros de la más ruin canalla que sustenta la tierra" (p. 53). El ingenioso equívoco consistente en entender 'de mulas' como si denotara una relación de servicio hace posible la inducción sofística, que luego desemboca en diatriba graciosamente exagerada: "Una vez [...] caminé en una mula de alquiler tal, que le conté ciento y veinte y una tachas, todas capitales y enemigas del género humano"' ¿Censura severa o pirotecnia ingeniosa? Como remate de un sermoncillo sobre los que pervierten los valores bautizando virtudes o vicios con nombres que no les cuadran, Rufo se vale de una inducción semejante para aplastar a un hidalgo tonto que murmura de la locuacidad de su hermano discreto: "vuestro hermano habla mucho y bien, y vos, poco y mal; y, siendo así, él sabe callar, y vos sois un palabrero"' (p. 309). Pasemos a ejemplos de inversión u oposición paradójica. Vidriera dice a uno que lleva sillas de manos: "Sabe cada uno de vosotros más pecados que un confesor; masa es con esta diferencia: que el confesor los sabe para tenerlos secretos, y vosotros, para publicarlos por las tabernas" (pp. 51-52). La comparación sorprendente, incluso chocante, aumenta la carga de indignación cuando queda aclarada la antítesis real que recubre la semejanza ${ }^{30}$. En este caso el intento de censurar se hace trans-

${ }^{30}$ Una comparación análoga está desarrollada en un soneto satírico de Quevedo: "Ya los pícaros saben en Castilla/cuál mujer es pesada y cuál liviana [...]", en Obras completas, t. 1, Poesia original, ed. J. M. Blecua, Planeta, Barcelona, 1963, p. 563. Según me dice mi amiga Teresa de Carlos, los taxistas madrileños tienen en la actualidad la misma mala fama que sus precursores de antaño, prueba de que la literatura ha bebido de un manantial real e 
parente. Se encuentran antítesis de tipo y tono análogos en Rufo. Ésta, por ejemplo, a propósito de los ladrones, "que por ser la infamia y hez de la tierra, renuncian en todos los oficios la honra que pudieran tener siendo hombres de vida santa y ejemplar" (p. 704). En cambio, en el dicho siguiente, el efecto escandaloso de los contrastes (régimen monástico/régimen del arriero, etc.) apunta a una indignación más aparente que real; lo que priva aquí es la observación costumbrista y la busca de simetrías elegantes, muy perceptible en las asonancias y aliteraciones. Vidriera falla sobre los arrieros: "Son gente que ha hecho divorcio con las sábanas y se ha casado con las enjalmas; son tan diligentes y presurosos, que a trueco de no perder la jornada perderán el alma; su música es la del mortero; su salsa, la hambre; sus maitines, levantarse a dar sus piensos; y sus misas, no oír ninguna" (p. 54). En la colección de Rufo, hay muchos apotegmas de aire satírico en los que priva de modo igual el rebuscamiento conceptista: "Tratándose de los copetes que algunos daban en usar, dijo «que eran higas para los que eran calvos, y muy mal estofo para las celadas, y aun cometa que amenazaba la ferocidad de los españoles»" (p. 454). Como el problema que me ocupa es el de distinguir la mordacidad ingeniosa de la sátira verdadera, he hecho caso omiso de aforismos sentenciosos, elogios y retruécanos, que presentan un aspecto muy parecido en ambas colecciones.

Para Cipión es "difícil cosa el no escribir sátiras". Y para Cervantes, al menos en el terreno moral/social, era difícil escribirlas. Por ello suele fundir la sátira con géneros o especies lindantes: apotegma, apólogo, "comedia", fábula apuleya, novela picaresca. Resulta extraño emitir este juicio sobre un escritor a quien la posteridad hubo de canonizar como un maestro del género. Pero quizás no tan extraño. Fue sin duda esa propensión suya a convertir las especies en universales, las cabezas de turco en personalidades diferenciadas, la que hizo posible la apoteosis.

Anthony Cliose University of Cambridge

intrahistórico. A Teresa le debo no sólo esta información sino el haber leído este artículo y hecho valiosas sugerencias sobre el estilo y contenido del mismo. 